\title{
Tanzanian Christian eco-ethics: Beyond ethics and theology
}

\section{Book Title: \\ Towards a credible environmental ethics for Africa: A Tanzanian perspective

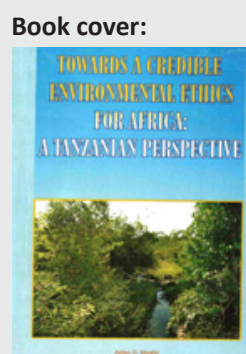 \\ Author: \\ Aidan G. Msafiri \\ ISBN: \\ 9966-909-53-2 \\ Publisher: \\ CUEA Publications (Kenya 2007) \\ Review Title: \\ Tanzanian Christian eco- \\ ethics: Beyond ethics and theology \\ Reviewer: \\ Jean du Toit ${ }^{1}$ \\ Affiliation: \\ ${ }^{1}$ School of Philosophy and Ethics, North-West University, South Africa \\ Email: \\ jean.dutoit@nwu.ac.za \\ Postal address: \\ PO Box 208, Building F13 \\ 2520, South Africa \\ How to cite this book review: Du Toit, J., 2012, 'Tanzanian Christian eco-ethics: Beyond ethics and theology', Koers - Bulletin for Christian Scholarship 77(2), Art. \#343, 2 pages. http://dx.doi. org/10.4102/koers.v77i2.343}

C 2012. The Authors. Licensee: AOSIS OpenJournals. This work is licensed under the Creative Commons Attribution License.
Rev. Dr. Aiden G. Msafiri presents a compelling perspective on issues of environmental ethics which are not only prominent in the industrialised Western world, but also in Africa and in Tanzania - the latter being the specific focus of the work. The book illustrates the unique role that African Christian eco-ethics and theology may play in addressing and curbing the growing ecological crisis in Tanzania. Msafiri's argument is not only pertinent for Tanzania, however; it is also applicable to the broader African context and to other non-African developing countries. He aims to engage various issues in the environmental development of such countries by providing a new paradigm, one that integrates traditional ethics approaches and theological perspectives.

The book is multidisciplinary in nature and allows broad evaluation, reflection and articulation of the environmental problems in Tanzania from a variety of sources, from the Biblical and the philosophical to the economic (to name but a few - the book lists several more). The range of varied perspectives are brought together to provide a very readable and fascinating view of the issues at hand. The book is certainly a worthwhile continuation of other work done in the field of global eco-ethics, but is also an important contribution to African eco-ethics (a field that is sometimes underrepresented and easily misunderstood when taken out of the context of the Traditional African worldview by Western scholars). Furthermore, it highlights a growing ecological concern and awareness in the Christian community.

The work has five chapters. The first chapter describes Tanzania's environmental crisis, presenting an empirical analysis of the nature and intensity of the ecological issues at stake, and is a great primer for an audience who may be unfamiliar with the Tanzanian environmental situation. This chapter is the foundation for the rest of the book and gives the reader a clear idea of the issues that are at stake in that country (and, more broadly, in other developing countries).

The second chapter provides a systematic investigation into different human reflections on the environment, such as the Traditional African perspective, Greek perspectives and Islamic views. These sections are particularly engaging because they present varied perceptions concerning the environment with which the reader may not be familiar. The Traditional African perspective takes the main stage throughout the book and especially in this chapter, which allows the work to carve a unique niche among the generally American-European approaches to environmental ethics. The foundational elements of Christian eco-ethics, which include several moral principles derived from Christian theology, are presented in the next chapter and link strongly to the systematised anthropological approach presented in chapter two.

Chapter four presents the main argumentative chunk of Msafiri's perspective: A fundamental integration between theological and ethical views. I found this section of the work very intriguing and, indeed, inspiring. It is sometimes difficult to merge different viewpoints that approach the same subject, and I think that Msafiri does an admirable job in this part of the book. Casual consideration of the ethical and theological perspectives may suggest that the two viewpoints can be amalgamated easily, but the opposite is often true. Msafiri, however, skilfully sketches a path that integrates these two viewpoints satisfactorily.

Msafiri continues his broad multidisciplinary approach in the fourth chapter, where he introduces several fascinating topics, such as eco-feminism, globalisation and the myths of unlimited growth and technological advancement in a coherent - although sometimes slightly brief - fashion. I particularly appreciated two sections in this chapter. The first is titled 'Negative beliefs towards certain animals and bird species', which investigates the role that Traditional African beliefs play to negatively influence biodiversity. This idea is profoundly stimulating, and although briefly discussed in the book, provides a vital perspective on African eco-issues that is simply not to be found in Western works of this nature. The second section that caught my attention is entitled 'An African eco-feminist model', which is a powerful theme explored in some detail throughout the 
chapter. Indeed, I feel that this argument is so highly relevant to the African context that the book may have been enhanced had this aspect been investigated even more thoroughly. The section also does not challenge the traditional patriarchal approaches associated with a Traditional African worldview as foundationally - or perhaps philosophically - as I had hoped, an approach which I believe may have been appropriate in this chapter of the work. (However, the topic is expanded upon when Msafiri describes the efforts made to safeguard the rights of women working in Africa and in the Church environment, and a section of the book is dedicated to 'Oppression of women and its ecological interconnections and implications'.)

The book concludes with practical role models that suggest how each person, regardless of their sphere in society, may attempt to address the environmental dilemmas discussed in the book. This provides a practical dimension to the book, and presents concrete suggestions and recommendations - a welcome development of Msafiri's argument.
The book as a whole benefits greatly from its multidisciplinary approach, which gives the reader a much broader view of the issues at stake than would otherwise have been possible. Of great importance is the idea that an ecological crisis is not simply a factor in developed Western countries (where one may expect misuse of natural resources as a means to sustain the developed social-economic framework of such a country), but that it is also an important aspect in developing African countries. In my view it is crucial to take note of this idea, as ecological crises have the potential to stunt the growth of entire developing nations. How should one then approach these environmental crises in the developing world? As Msafiri says early in his book: Therapy of the environment is not and cannot only be confined to the realm of science and technology; the issue is of a moral nature. The role that theology plays in this regard is established by Msafiri in the book. This is the new paradigm that he refers to, a way to answer a wide range of questions in environmental ethics that stretches beyond the boundaries of traditional disciplines and merges ethical theory and theology. 